\title{
AS NARRATIVAS “CÉLTICAS” DE VIAGEM PARA O OUTRO MUNDO (ECHTRA; IMMRAM; LONGES E FÍS): FONTES HISTÓRICAS PARA UMA HISTÓRIA CULTURAL DA IRLANDA ANTIGA E MEDIEVAL
}

\section{Introdução}

\section{Dominique Vieira Coelho dos Santos ${ }^{1}$}

Da forma como nos chegam, os fragmentos do passado são caóticos $e$ desorganizados, não tem uma coerência interna, assim, precisam ser, então, agrupados, ordenados e sistematizados em uma narrativa plausível e coerente. Segundo Luís Costa Lima, é o historiador quem tem esta função, pois é somente por meio desta sistematização narrativa que "o diverso, o acidental $e$ o irregular entram em uma ordem"2. É a comunidade dos historiadores profissionais, a partir de seus critérios de validação, que avalia a produção destas narrativas, capazes de gerar verdades e certezas de caráter relacional, rejeitando-as ou não ${ }^{3}$.

A própria maneira como a Ciência da História tem sido produzida ao longo do tempo pode ser historicizada. Por isso, o passado, mas também a relação deste com o presente e com as mais diversas expectativas de futuro, tem sido constantemente repensado, tanto pelas versões científicas quanto não científicas da História.

Estas reflexões, sempre respostas a contextos específicos, produziram inúmeras transformações no campo historiográfico. Talvez uma das principais seja o alargamento do que entendemos como sendo um documento e/ ou fonte histórica.

Assim sendo, é possível afirmar que a compreensão da noção de fonte histórica para além da documentação apenas escrita tornou-se um paradigma na Ciência da História, pois apenas com muita dificuldade alguém poderia tentar convencer a comunidade dos historiadores profissionais do contrário. Isto significa o abandono da ideia de que para fazer História seria mandatório a utilização de tratados de governo, ofícios diplomáticos, cartas oficiais etc., em favor da noção de que qualquer indício, e/

\footnotetext{
${ }^{1}$ Professor de História Antiga na FURB - Universidade Regional de Blumenau, onde também coordena o LABEAM - Laboratório Blumenauense de Estudos Antigos e Medievais. É membro do LEIR Laboratório de Estudos Sobre o Império Romano e da Cátedra de Estudos Irlandeses W.B. Yeats, ambos da USP. O artigo em questão se originou a partir de alguns resultados do projeto de pesquisa 531/2016, subsidiado pela Propex/FURB, e foi realizado com apoio financeiro da CAPES Coordenação de Aperfeiçoamento de Pessoal de Nível Superior - Brasil, Estágio PósDoutoral/Processo no 88881.119892/2016-01, e da própria Universidade de Blumenau, por meio da concessão de afastamento integral para capacitação, Portaria n ${ }^{\circ}$ 950/2016, possibilitando período sabático de 1 ano na qualidade de Visiting Scholar junto ao Oxford Centre For Late Antiquity a convite de Bryan Ward-Perkins. O auxílio dos bibliotecários Janet Foot (Celtic Collection/ Taylor Institution Library) e Owen McKnight (Jesus College Celtic Library) foi fundamental na localização de parte do material consultado. De igual modo, agradeço a Thomas Charles-Edward tanto pelos diálogos quanto pelo convite para utilização da Jesus College Celtic Library. Qualquer equívoco e imperfeição encontrados neste artigo são, evidentemente, de minha única e exclusiva responsabilidade. E-mail: vieiradominique@hotmail.com.

${ }^{2}$ COSTA LIMA, Luís. A Aguarrás do tempo. Rio de Janeiro: Rocco, 1989, p. 17.

${ }^{3}$ MARTINS, Estevão Rezende. "Veritas filia temporis? O conhecimento histórico e a distinção entre filosofia e teoria da história". Síntese, Belo Horizonte, v. 34, 2009, p. 5-34.
} 
ou vestígio, da presença humana poderá, desde que relacionado a um problema de pesquisa e um conjunto específico de perguntas, servir como testemunha de eventos passados que, uma vez interrogados, auxiliarão o historiador a compreender como outras sociedades no tempo $e$ no espaço produziam orientação $e$ sentido para sua própria existência ${ }^{4}$.

Uma vez que a transformação desta infinidade de coisas que ocorreram no passado em História não é um processo automático, importa compreender, então, como surge dos feitos a História. A própria noção do que seria um "fato histórico" é muito debatida na Galáxia de Heródoto. Por isso, o campo está sempre aberto para novas investigações, perspectivas e temáticas ${ }^{5}$.

É neste contexto que, além das nuances produzidas pelas historiografias nacionais de cada lugar, vimos surgir também diferentes correntes e formas explicativas para as experiências humanas no tempo, muitas vezes compartilhadas em escala internacional. São saberes e fazeres historiográficos geralmente categorizados como: História Econômica, História Política, História Social etc., e, ainda, inúmeras fragmentações em campos temáticos, tais como: História das minorias, História das mulheres, História das religiões etc. José D'Assunção Barros decidiu sistematizar este "Campo Histórico" a partir de três nomenclaturas: "Abordagens" (História Oral, História Serial, Biografia etc.); "Domínios" (aqui o autor insere História das mulheres, das religiões etc.); e "Dimensões" (Geo-História; História Demográfica, História Política etc. $)^{6}$. É nesta última categoria que se insere a chamada História Cultural com suas ramificações.

Peter Burke classificou a História Cultural em quatro fases: uma primeira, que ele chamou de "Clássica", que vai de 1800 a 1950; a segunda fase, a partir de 1930, relacionada com História da Arte; a terceira, a partir de 1960, quando era vigente, naquele momento, a divisão entre cultura popular e erudita, sendo a primeira objeto principal da História Cultural do período; e, por fim, a quarta fase, chamada de "Nova" História Cultural, que teria se desenvolvido a partir de 1980, ou seja, nas últimas décadas do século $\mathrm{XX}^{7}$.

Recorrendo ao diálogo com outras disciplinas, uma tendência desde a década de 1930, com a assim chamada Escola dos Annales, principalmente com a Antropologia, mas sem deixar de lado a Linguística e a Psicologia, esta "Nova" História Cultural (última fase da classificação de Burke), tem possibilitado o surgimento de novos objetos de investigação ou a revisitação de temas mais tradicionais, porém, agora, com outros olhares, gerando novas perspectivas historiográficas.

Desde as inúmeras referências que Marc Bloch fez em suas obras, hoje clássicas, "A Sociedade Feudal", "Os Reis Taumaturgos" e "Apologia da História" sobre "as

${ }^{4}$ RÜSEN, Jörn. Razão histórica: teoria da história I: os fundamentos da ciência histórica. Brasília (DF): Ed. da UnB, 2010, 194p.; RÜSEN, Jörn. Reconstrução do passado: teoria da história II: os princípios da pesquisa histórica. Brasília (DF): Ed. da UnB, 2010, 187p.; RÜSEN, Jörn. História viva: teoria da história III: formas e funções do conhecimento histórico. Brasília (DF): Ed. da UnB, 2010, 159p.

${ }^{5}$ BARROS, José D'Assunção. "Fontes Históricas: um caminho percorrido e perspectivas sobre os novos tempos". Revista Albuquerque, v. 3, n. 1, 2010.

${ }^{6}$ BARROS, José D'Assunção. O projeto de Pesquisa em História: da escolha do tema ao quadro teórico. Petrópolis: Vozes, 2012.

${ }^{7}$ BURKE, Peter. O que é História Cultural? Trad. Sergio Goes de Paula. Rio de Janeiro: Jorge Zahar Editora. 2008. 
formas de sentir e pensar", que apareciam sob diversas alcunhas (espírito, atmosfera mental, fatos psicológicos, estados de alma etc. $)^{8}$, passando por noções como "História das mentalidades", "Imaginário" e "Imaginário Social", até as utilizadas mais recentemente, como as noções de "práticas culturais" e "representações sociais", sobretudo depois da tradução da obra de Roger Chartier ${ }^{9}$ para o português, o estudo das sociedades Antigas e também Medievais tem não somente acompanhado estas mudanças, como delas participado diretamente, já que vários autores que colaboraram para este debate eram Antiquistas ou Medievalistas, como Jean-Pierre Vernant, Marcel Detienne, Georges Duby, Jacques Le Goff, dentre outros. Isto fez com que novos conceitos e noções fossem ou elaborados ou integrados ao vocabulário destas duas áreas específicas do saber histórico, colaborando, assim, para sua constante renovação.

Neste artigo, refletimos sobre alguns destes aspectos. Considerando a sistematização Medieval de classificação das narrativas produzidas na Irlanda neste arco cronológico específico e dialogando com a historiografia da área, abordamos as narrativas "célticas"10 de viagens para o outro mundo (Echtra, Immram, Longes, Fís), apontando como fontes literárias podem ser utilizadas para a escrita de uma História Cultural da Irlanda Antiga e Medieval.

\section{As listas medievais " $A$ ", " $B$ " $e$ " $X$ ": algumas considerações sobre os sistemas de classificação da literatura irlandesa Antiga e Medieval}

Assim como temos, na modernidade, várias obras cujos objetivos são produzir sistemas classificatórios, desde palavras, como os dicionários, até o próprio conhecimento, caso das enciclopédias, autores que viveram em outras temporalidades também produziram suas classificações.

Podemos considerar que a literatura irlandesa Antiga e Medieval é dividida, hoje, em geral, em três grandes blocos: um contendo quatro ciclos textuais (Ulster, Feniano, Mitológico e Histórico); outro que engloba aventuras, viagens e visões; e um terceiro que contempla a poesia ${ }^{11}$.

Se olharmos para as classificações pré-modernas destas narrativas, no entanto, veremos que elas são diferentes, utilizam-se de outras nomenclaturas, o que acaba proporcionando uma forma distinta de percepção destes relatos, talvez mais próxima

${ }^{8}$ BLOCH, Marc. Apologia da história ou o ofício do historiador [1949], trad., Rio de Janeiro: Jorge Zahar, 2001; BLOCH, Marc. La société féodale [1939-1940], Paris: Albin Michel, 1949. Tradução portuguesa: A sociedade feudal, Lisboa, Edições 70, 1979. BLOCH, Marc. Les Rois thaumaturges Étude sur le caractere surnaturel attribué à la puissance royale, particulièrement en France et en Angleterre, Strasbourg, publ. de la faculté des lettres de l'Université de Strasbourg, 1924, in- $8^{\circ}, 542$ p. 4 Pl. Tradução Brasileira: Os Reis Taumaturgos. São Paulo: Companhia das letras, 1993.

${ }^{9}$ CHARTIER, Roger. A História Cultural: entre práticas e representações. Lisboa: DIFEL, 1990. Para um debate mais aprofundado sobre este conceito ver: SANTOS, Dominique. "Acerca do Conceito de Representação". Revista de Teoria da História, v. 6, 2011, p. 27-53.

10 "Celta/céltico/celticidade/celtologia" são denominações amplamente problematizadas a partir de várias vertentes teóricas tanto na História quanto em outras áreas do saber. Para uma introdução ao debate, ver: SANTOS, Dominique. "Forma e Narrativa - uma reflexão sobre a problemática das periodizações para a escrita de uma História dos Celtas". Nearco (Rio de Janeiro), v. VI, 2013, p. 203-228.

${ }^{11}$ Cf. DILLON, Myles. Early Irish Literature (London, 1948, repr. Dublin, 1995) e, mais atualmente, Ní BHROLCHÁIN, Muireann. An Introduction to Early Irish Literature. Dublin: Four Courts Press, 2009. 
do sistema de representação adotado pelos autores que escreveram e/ou copiaram estas narrativas.

Nosso conhecimento acerca desta divisão medieval foi possível porque três listas nos chegaram daquele período: duas principais e mais antigas, que, segundo Rudolf Thurneysen, derivam de uma mesma lista mais antiga, provavelmente do século $\mathrm{X}^{12}$; e uma terceira, posterior, e menos mencionada, denominada de "lista x"

A primeira delas é referenciada pela historiografia específica da área como "lista a" e está disponível em dois Manuscritos: o Trinity College Dublin, Manuscrito 1339, também chamado de Book of Leinster, lugar em que foi produzido no século XII, Secção H 2.18, páginas 189b-190b, nas quais se encontra a lista. Todos estes manuscritos são, geralmente, mencionados de maneira abreviada, forma de referência comumente aceita internacionalmente como: TCD, MS 1339 - H 2.18 Book of Leinster [s. xii], pp. 189b-190b; o segundo manuscrito, já adotando sua forma abreviada de referência, é o: TCD, MS 1336 - H 3.17 [s. xvi], col. 797) ${ }^{14}$.

A segunda lista é chamada de "lista b" e está disponível em três manuscritos: o primeiro deles, é conhecido como RIA, MS 23 N 10 - Betham 145967 [s. xvi], p. 2932; o segundo, pertencente à biblioteca da Universidade de Oxford, é o Oxf. Bodleian Lib., MS Rawl. B.512 [s. xv/s. xvi], ff. 109r, col. 2 - 111r col 1; o terceiro e último é o British Lib., MS Harl. 5280 [s.xvi], ff. 47 e 58rv) ${ }^{15}$.

A terceira, embora menos mencionada, denominada como "lista x", é derivada de dois manuscritos: National Library of Scotland, Adv, MS 72.1.7, Gaelic VII, f. 7rb, texto do século XV; e o segundo de uma introdução tardia, datada do século XVI, feita para o conjunto de leis conhecidas como Senchas Már: British Library, MS Harleian 432 [s. xvi], f. $3 \mathrm{~d}^{16}$.

A partir de uma introdução feita pelos autores destes manuscritos é possível perceber que eles falam da habilidade dos poetas em contarem estes relatos, que teriam memorizado. Trata-se de saber quantas narrativas poderiam ser recitadas por esta via.

A partir dos manuscritos do Book of Leinster e do TCD MS H 3.17, por exemplo, lemos que o que se seguirá diz respeito "à qualificação dos poetas" com relação aos contos que este é capaz de narrar aos reis e que estes são em quantidade de "trezentos e cinquenta contos (350), sendo, dentre estes, duzentos e cinquenta (250) contos maiores e cem (100) sub-contos" 17 . Todavia, de fato, nenhum dos manuscritos possuem esta quantidade. O Book of Leinster apresenta cento e setenta e oito (178) títulos e o TCD MS H 3.17 cento e oitenta e dois (182).

\footnotetext{
12 THURNEYSEN, Rudolf. Die Irische Helden- und Königsage bis zum siebzehnten Jahrhundert, Halle: Niemeyer, 1921, p. 21-24.

${ }^{13}$ MAC CANA, Proinsias. The learned tales of medieval Ireland, Dublin: DIAS, 1980, p. 33 e 38; e GROENEWEGEN, Dennis (Project director). CODECS - Online database and e-resources for Celtic Studies. Disponível em: <www.vanhamel.nl/codecs/Medieval_Irish_tale_lists>. Data de Acesso: 06/04/2017.

${ }^{14}$ MAC CANA, The learned (...).; GROENEWEGEN, (Project diretor). Codecs (....).

${ }^{15}$ MAC CANA, The learned (...).; GROENEWEGEN, (Project diretor). Codecs (....).

${ }^{16}$ MAC CANA, The learned (...).; GROENEWEGEN, (Project diretor). Codecs (....).

${ }^{17}$ TCD, MS 1339 - H 2.18 - Book of Leinster [s. xii], pp. 189b; TCD, MS 1336 - H 3.17 [s. xvi], col. 797); ver também: MAC CANA, Proinsias. The learned (...).
} 
Já o manuscrito da Royal Irish Academy apresenta um diálogo que teria ocorrido entre o rei e o poeta, por meio do qual ficamos sabendo que o poeta conclama poder contar qualquer um dos contos que o rei escolher. Tendo consentido o rei, o poeta, então, passa a "enumerar todos os contos que ele é capaz de narrar" para que o rei escolha "aquele que quer ouvir" ${ }^{18}$. Tanto a "lista a" quanto a "lista b" estão baseadas nestes princípios.

De acordo com a "lista a" existem dezessete (17) tipos de contos, já a "lista b" apresenta quinze (15). Na "lista a", tanto no manuscrito do Book of Leinster quanto do TCD MS H 3.17 estão catalogadas doze (12) categorias de textos, que formariam um eixo de contos principais, que, em irlandês, conforme lê-se nos dois manuscritos, são as seguintes: Togla; Tána; Tochmarca; Catha; Uatha; Imrama; Oitte; Fessa; Forbassa; Echtrada; Aithid; e Airggne. Podemos traduzir estas categorias para o português como: Destruições; Roubo de Gado; Cortejo; Batalhas; Terror; Viagens; Morte; Banquetes/Festins; Sítio/Cerco; Aventuras; Fuga e Pilhagem.

Compreender estas classificações é fundamental. O Táin Bó Cúailnge, por exemplo, obra bastante popular da literatura Medieval irlandesa, por vezes é mencionado de forma isolada como épico irlandês por excelência, uma espécie de "Ilíada" insular, ou como principal texto de um grupo de narrativas categorizadas como pertencentes ao "Ciclo de Ulster", adotando a perspectiva moderna. No entanto, a obra sequer é a única do gênero, há outras narrativas do tipo na literatura irlandesa ${ }^{19}$. Da "lista a" temos, além do Táin Bó Cúailnge, dez tána (plural de táin), de acordo com o manuscrito do Book of Leinster, ou nove, de acordo com o TCD MS H. 3.17, já que o escriba deste segundo manuscrito deixou de fora o T. Bó Crebain, que aparece no Book of Leinster. Já a "lista b" apresenta 4 tána, de acordo com o manuscrito RIA, MS 23 N 10; 6 tána, se observarmos o Oxf. Bodleian Lib., MS Rawl. B.512; e 5, se seguirmos o British Lib., MS Harl. 5280, já incluso o Táin bo Cúailnge.

$\mathrm{O}$ mesmo ocorre com as outras 11 categorias dentre os contos principais. Temos, então, além dos Tána (Roubo de Gado), de acordo com a "lista a", manuscrito do Book of Leinster, exemplos de Togla (Destruições): Togai Tige Nectain, Togail Bruidne Uí Dergga, Togail Bruidne Broin maic Briuin, Togail Bruidne Uí Dergga etc; de tochmarca (Cortejo): Tochmarca inso sís; Tochmarc Meidbe, T. nEmire, T. Ailbe etc.; de Catha (Batalhas): Catha Maige Tured, C. Talten, C. Maige Mucrima etc.; de Uatha (Terror): Uath Angeda, Uat Ecalsa, U. Licce Blada etc.; de Imrama (Viagens): Imrom Maele Duin, Imrom hua Corra, que aparecem na "lista a"; de Oitte (Morte): Aided com Ruí, Aided com Culaind, A. Conaill etc.; de Fessa (Banquetes/Festins): Fess Tige Fir Blai, F. Tige Bichair, F. Tige Tulchinme etc.; de Forbassa (Sítio/Cerco): Forbais Fer Fálga, F. Etair; F. Aiche, F. Dúin Bárc etc.; de Echtrada (Aventuras): Echtra Nera, E. Fiamain, E. Com Ruí etc.; de Aithid (Fuga): Aithed Mugaine re Fiamain, A. Derdrinne re macaibe Uislem, A. Aefe ingine Eogain re Mes Dead etc; $e$ de Airggne (Pilhagem): Argain Átha Hí, A. Dune Dubglaise, A. Dune Dubglaisse etc., a maior categoria.

\footnotetext{
${ }^{18}$ RIA, MS 23 N 10 - Betham 145967 [s. xvi], p. 29; ver também: MAC CANA, The learned (...).

19 SANTOS, Dominique; FARRELL, Elaine. "Táin Bó Cúailnge - Um Épico Irlandês". In: SANTOS, Dominique. (org.). Grandes Epopeias da Antiguidade e do Medievo. $1^{\text {a }}$ ed. Blumenau: Edifurb, 2014, p. 220-241.
} 
O escriba do Book of Leinster, no momento separado para catalogar narrativas de viagem (Imrama dā inso .i.), selecionou apenas três referências com título adequado para a categoria; mesmo comportamento adotado pelo escriba do TCD MS H. 3.17, que, ao fazer referência às narrativas de viagem (Imrama annso .i.), inseriu duas com título análogo ao da categoria. Após isto, tanto na "lista a" quanto na "lista b", o que vemos são "longes", narrativas de exílio, como se estas fossem uma sub-categoria das Immrama ou com elas se confundissem.

O Book of Leinster menciona quatro longes: Longes Breg Lèith, Longes Brecain, Longes Labrada e Longes Fothaid; o TCD MS H. 3.17 menciona 5, além das citadas no manuscrito do Book of Leinster, o escriba acrescentou a Longes Eithne Uathaige. Todos estes títulos aparecem no momento reservado para catalogar as Immrama. Ou seja, tomando a "lista a" como exemplo, dentre os oito relatos inseridos como "Imrama dā inso .i.", somente três portam o título "Immram/Immra": Immram curaig Máele Dúin (A viagem do barco de Maél Dúin); Immram curaig Ua corra (A viagem de Uí Corra); e Imram Luinge Murcetaig maic Earca (A viagem da embarcação de Muirchertach son of $\mathrm{Erc})^{20}$.

Considerando isto, há um grande debate sobre como classificar, por exemplo, uma das obras mais conhecidas deste gênero de viagens, a Immram Brain, pois, apesar da nomenclatura, além dela não aparecer na 'lista a' na categoria das Immrama (Imrama dā inso .i.), ela aparece na 'lista b' com o título 'Echtra Brain Maic Febail'.

Ou seja: seria a Immram Brain uma Immram ou uma Echtra? Qual a relação entre os dois gêneros textuais? Seria a Echtra uma primeira categoria, mais antiga, pagã, enquanto todas as narrativas de tipo Immrama seriam posteriores e cristãs? Trata-se de um dos principais tópicos do debate entre "nativistas", "anti-nativistas" e "pós antinativistas" desde a segunda metade do século passado na historiografia irlandesa ${ }^{21}$.

O problema parece derivar do próprio título em irlandês, cujas palavras analisadas colocamos propositadamente em negrito: "ImRam Brain maic Febail, ocus a Echtra andso Sís". Ou seja: "A Viagem de Bran filho de Febal, e sua expedição aqui abaixo", conforme edição Meyer e Nutt" ${ }^{\text {" }}$. Os próprios Meyer e Nutt, todavia, afirmam que uma Immram "denota uma viagem feita de forma voluntária, diferentemente de uma longes, uma viagem de exílio. Já a Echtra, por sua vez, denota especialmente uma viagem ou estadia em terras feéricas, como na Echtra Bresail Bricc maic Briuin"”3.

J.S. Mackley, no entanto, recorrendo à obra de Séamus Mac Mathúna, insiste no problema do título, pois acredita que o conflito resida mesmo no conteúdo misto derivado do título Immram Brain/Echtra Brain Maic Febail ou, conforme é mencionada em sua obra, "Immram Brain maic Febuil", que seria melhor

\footnotetext{
${ }^{20}$ WOODING. Jonathan M. (ed.). The Otherworld Voyage in Early Irish Literature - An Anthology of Criticism. Dublin: Four Courts Press, 2014.

${ }^{21}$ DUIGNAN, Leone. The Echtrae as an Early Irish Literary Genre. PH D Degree (PH D in Celtic Studies). NUI MAYNOOTH. Maynooth, 2010; DUMVILLE, David N. Echtrae and Immram: Some Problems of Definition. Ériu, vol. 27, 1976, pp. 73-94.

${ }^{22}$ MEYER, Kuno, and Alfred Nutt, The voyage of Bran, son of Febal to the land of the living, 2 vols, Grimm Library 4, 6. London: Nutt, 1895-1897, p. 02-35.

${ }^{23}$ Meyer, Kuno, and Alfred Nutt, The voyage of Bran (...), p. 02.
} 
compreendida como parte de uma categoria "híbrida, que contém ambos elementos: relacionados com as Immrama e as Echtrae ${ }^{24}$.

Leone Duignan, que estudou o tema em sua Tese de Doutorado, afirma que várias narrativas tem o mesmo problema, não se trata de uma particularidade da Immram Brain. A 'lista a' e a 'lista b' mencionam 21 títulos para a categoria das narrativas que podem ser consideradas Echtrae, por exemplo. Destes, seis sobreviveram: Echtra Nerai (EN); Echtra Loegairi (EL); Echtra Chonnlai (EC); Echtra Airt (EA); Echtra Cormaic maic Airt (ECA); e Echtra mac nEchach Mugmedon (EEM). No entanto, há várias obras que não tem "Echtra" no título e, por isso, não foram contabilizadas, mas que, em sua totalidade ou em parte, podem ser consideradas como pertencentes a este gênero. São os textos: Baile in Scáil (BS), the Five Lugaid's (FL), Tochmarc Emre (TE), Serglige Co Culainn (SCC), Siaburcharpat Con Culaind (SbCC); e a própria Immram Brain (IB) ${ }^{25}$.

Qualquer que seja a categoria escolhida para alocar determinado texto parece sempre insuficiente, gerando alguma dissonância. Assim, esta dificuldade de classificação é bastante evidente para os leitores modernos. É possível que ela tenha sido menos incisiva para os poetas medievais, já que teriam mais habilidade em operar um sistema que lhes era familiar.

São muitos os desafios de se trabalhar com esta temática, pois o pesquisador decidido a enfrentá-los terá que ficar atento a todos estes detalhes, uma conditio sine qua non para interpretação destas fontes históricas. Todavia, como nos advertiu Kim Maccone, não devemos tomar estes gêneros de classificação tão ao pé da letra, compreendê-los tendo em vista o contexto para o qual foram produzidos já seria suficiente, pois, do contrário, todo o esforço empreendido não passará de um "fútil exercício taxonômico" 26 .

Apesar de haver equivalência entre alguns títulos das listas medievais e o sistema de classificação moderno, a escolha feita neste artigo foi manter as nomenclaturas medievais destas narrativas, que é como elas aparecem nos manuscritos. Das várias narrativas categorizadas nestas listas medievais, principalmente na 'lista a' e 'lista b', nos interessam as narrativas "célticas" de viagens para o outro mundo, que aparecem denominadas como Echtra, Imram, Longes e Fis. Nos sistemas modernos de classificação, embora com variações, a maior parte delas está no que denominamos de "segundo bloco", que engloba "aventuras, viagens e visões".

Uma vez compreendido este debate e não tomando as definições apresentadas como entidades fixas e imutáveis, mas apenas uma breve tentativa de sistematização para efeitos didáticos é possível apontar as Echtrae como aventuras humanas, uma espécie de jornada do herói para o outro mundo, geralmente uma terra feérica; As Immrama, por sua vez, aborda uma espécie de viagem de penitência, cujo foco é a própria viagem, geralmente marítima, para visitação de ilhas neste outro mundo "céltico". "Immram" pode até mesmo ser uma tradução de "Navigatio" para a língua

\footnotetext{
${ }^{24}$ MACKLEY, Jude S. The Legend of St Brendan - A Comparative Study of the Latin and Anglo-Norman Versions. Bril, Leiden/Boston, 2008. P. 21. Cf. Também: MAC MATHÚNA, Séamus. Immram Brain: Bran's Journey to the Land of the Women. Tübingen: M. Niemeyer, 1985, p. 279.

${ }^{25}$ DUIGNAN, Leone. The Echtrae (...), p. 16.

${ }^{26}$ MACCONE, Kim. Pagan past and christian present in early Irish literature. Maynooth Monographs vol. 3. Maynooth: An Sagard 1990, xii + 277PP.
} 
irlandesa; as Longes são viagens de exílio, feitas de forma não voluntárias; por fim, Fís/Físis pode ser traduzido como "Visão" para o português, e pode ser o equivalente irlandês do latim "Visio". Considerando isto, vejamos, então, como estas obras podem ser utilizadas para o estudo da História da Irlanda Antiga e Medieval a partir da ótica da História Cultural.

\section{As Narrativas "Célticas" de Viagem para o Outro Mundo: Fontes para uma História Cultural da Irlanda Antiga e Medieval}

Dentre os inúmeros contos que tem como temática estas narrativas de viagem para o outro mundo ${ }^{27}$, categorizadas e/ou memorizadas e sistematizadas por escrito pelos poetas medievais irlandeses a partir da atribuição de títulos como: "Echtra", "Immram", "longes "e "Fís", selecionamos quatro obras específicas para nossa análise: a "Echtra Nerai (EN)"/As aventuras de Nera; Immram Brain/A viagem de Bran; a Longes mac n-Uislenn/ O exílio dos filhos de Uisliu; e, por fim, a Fís Adamáin/Visão de Adamnán. De modo a facilitar a compreensão, separamos cada obra em um subtópico, que apresentamos a seguir.

\section{Echtra Nerai}

A narrativa denominada de Echtra Nerai/As aventuras de Nera é o título de uma obra que, como o próprio nome sugere, conta as aventuras de $\mathrm{Nera}^{28}$. O conto data provavelmente do século X/XI e nos chegou a partir de manuscritos do século XIV e XV: British Library, MS Egerton, 1782, [1516-1518], ff. 71v-73v; Trinity College, MS 1318, 16 (cols 573-958), (H 2. 16), que é uma secção do Yellow Book of Lecan [s. xiv/xv], pp. 60a linha 42 - 62a cols 658-662. O título da obra neste manuscrito é Táin bé Aingen; e Royal Irish Academy, MS 23 O 48b (476), parte 2 do Liber Flavus Fergusiorum, [c. 1435-1440], p. 51rb-51va (ou 102rb-102va), um fragmento incompleto e sem título ${ }^{29}$.

A Echtra Nerai pode ser resumida da seguinte maneira: Na noite de Samhain, festa céltica que marca o início do solstício de inverno, quando os guerreiros de Ráth Cruachan, lugar mais importante de Connacht, estavam no meio de um banquete, o Rei Aillil ofereceu um prêmio para alguém que tivesse a coragem de colocar uma faixa de vime no tornozelo de qualquer um dos dois cadáveres que tinham sido enforcados no dia anterior. Nera foi o único que aceitou este desafio, após munir-se de armadura e elmo. Quando Nera cumpre seu objetivo, o morto se torna para ele pedindo um pouco de água, algo que ele parece ser obrigado a cumprir, e, a partir deste momento, uma série de acontecimentos se desenrola, gerando, inclusive, várias

${ }^{27}$ Uma discussão mais geral sobre a noção de "outro mundo", tal como apresentado na literatura medieval, pode ser encontrada nas sistematizações elaboradas pela historiografia da área. Cf. PATCH, Howard Rollin. The Other World according to descriptions in medieval literature. Cambridge, MA: Harvard UP, 1950. New York: Octagon, 1970.

${ }^{28}$ Disponível bilíngue irlandês/inglês em: MEYER, Kuno (ed. and tr.). "The adventures of Nera", Revue Celtique 10, 1889, p. 212-228, 520. Corrigenda in Revue Celtique 17: 319. Digitalizado no link: <http://archive.org/stream/revueceltique10pari\#page/214/mode/1up>. Data de Acesso: 06/04/2017.

${ }^{29}$ GROENEWEGEN, (Project director). CODECS - Online database and e-resources for Celtic Studies. Disponível em: <www.vanhamel.nl/codecs/Medieval_Irish_tale_lists > . Data de Acesso: 06/04/2017. 
mortes, e quando Nera, após devolver o cadáver ao seu lugar, retornou para Cruachan viu que tudo havia sido incendiado e os guerreiros decapitados por um exército do Síd, o outro mundo céltico. Ao seguir estes guerreiros, Nera foi parar no próprio Síd. O rei daquele lugar ordena que Nera trabalhe para ele carregando lenha e viva ali com uma das mulheres locais, certamente um ente feérico. Nera passa, então, a viver com ela, que lhe revela que tudo o que vira nada mais foi do que uma visão do que ocorreria dentro de um ano caso ele não advertisse seu povo, avisando o Rei Aillil e a rainha Medb, de que deveriam marchar com seu exército contra o Síd, única maneira de evitar tal acontecimento. Nera assim o faz e, quando volta para Cruachan, descobre que, embora tenha passado três dias e três noites no Síd, nenhum tempo passou para os que ficaram aguardando seu retorno. Seguindo as instruções de Nera, chegado o tempo, o exército de Cruachan se prepara para marchar contra o Síd. Antes, porém, Nera retorna para lá para buscar seus pertences antes que o ataque ocorra. Chegando no Síd, todavia, Nera descobre que a mulher com a qual vivera dele tinha tido um filho e dado a este filho uma vaca. Morrígan, divindade feminina céltica da guerra, roubou esta vaca e a levou para que se tornasse prenha de Donn Cuailnge, o touro castanho de Cooley, com o qual teve um bezerro. $\mathrm{O}$ exército de Connacht ataca o Síd tomando de lá vários tesouros e Nera fica naquele lugar com seu povo, onde permanecerá até o fim do mundo ${ }^{30}$.

Um texto desta natureza, apesar de sua utilização pelos estudos célticos, sobretudo na literatura, na folclorística etc., costumava não ser considerado importante para a escrita da História, pois apenas com muita dificuldade, se é que isto pode ser feito, poder-se-ia dele extrair referências aos "fatos" e "datas interessantes" para produção de uma narrativa histórica com viés político, em sentido tradicional, ou até mesmo ligado a uma História Econômica. Todavia, após as mudanças nas concepções historiográficas, já delineadas no início deste artigo, textos como a Echtra Nerai também passaram a ser contemplados pelo holofote historiográfico, pois podem ser evidências significativas para uma História cultural da Irlanda Antiga e Medieval.

As narrativas literárias sobre a relação de proximidade e separação entre os mundos e o constante relacionamento entre eles têm chamado atenção dos historiadores. Como resultado, este tipo de temática (o diálogo e interação com os mortos; a guerra entre exércitos de mundos diferentes; a relação dos entes feéricos com os seres humanos deste mundo; as características gerais e particulares deste outro mundo céltico etc.), antes ausente dos livros de História, agora é cada vez mais frequente.

Várias nomenclaturas têm sido utilizadas para descrever o "Síd": Inis Subai (A ilha da alegria; Tír na mBeó (Terra dos viventes); Tír na mBan (Terra das mulheres); Mag Mell (Planície do prazer); Mag Mór (A grande planície); In Tír Tairngire (A terra

${ }^{30}$ Esta versão para o leitor de língua portuguesa foi feita a partir da combinação das traduções $e$ interpretações da narrativa para língua inglesa feitas por Meyer e Carey nas seguintes obras: E MEYER, Kuno (ed. and tr.). "The adventures of Nera" (...); CAREY, John. Sequence and Causation in Echtra Nerai. Ériu, vol. 39, 1988, p. 67-74. Quando Meyer publicou sua tradução, em 1889, ele se baseou no manuscrito MS Egerton, 1782, [1516-1518], ff. 71v-73v e citou o Trinity College, MS 1318, 16 (cols 573-958), (H 2. 16), únicos que ele conhecia à época. Meyer, na obra citada, comenta divergências e disponibiliza uma transcrição do texto em irlandês do Liber Flavus Fergusiorum. Quem desejar seguir com o estudo da Echtra Nerai terá como primeira tarefa explorar de forma detalhada estas variantes de manuscritos, que podem interferir na maneira como a narrativa é contada. 
prometida) e Tír na nÓg (Terra da Juventude) $)^{31}$. Segundo Muireann Ní Bhrolcháin, a existência de vários termos pode indicar uma pluralidade de mundos em distintas versões dentro da tradição irlandesa ${ }^{32}$.

A separação entre estes dois mundos neste tipo de relato é diferente, por exemplo, do cristianismo. Na religião monoteísta, embora existam alguns exemplos de situações semelhantes a enfrentada por Nera (Enoque; Saulo; Jesus no monte da transfiguração etc.), é preciso esperar pela morte para se ter acesso a algo desta natureza. Já nas narrativas "célticas" este é um tema comum.

É possível perceber na Echtra Nerai que são dois lugares em contato permanente e pode-se adentrá-lo, encontrar pessoas que já morreram, reis do outro mundo, fadas e outros personagens daquele contexto. O tempo para Nera é diferente do tempo do rei, que fica em Cruachan, pois para o primeiro ele passa, já para o segundo permanece igual, tudo ao mesmo tempo. O Síd é acessível para qualquer pessoa, sem necessidade de separação entre corpo e alma ${ }^{33}$. O fato de Nera ter esta experiência está relacionado apenas a ele ser o único a aceitar o desafio, tornando-se, assim, habilitado a romper estas instâncias e realizar proezas $e$ fatos admiráveis, características próprias do herói, empreendendo uma jornada particular: partida, aventura importante, neste caso dando nome à narrativa, realização de proezas e retorno para contá-las ${ }^{34}$, com a diferença de que Nera vai outra vez para o Síd e escolhe viver neste outro mundo de uma vez por todas. Todavia, tais experiências estariam também disponíveis a outras pessoas, caso elas tivessem a mesma coragem de Nera.

Situações e contextos como estes que podemos identificar na Echtra Nera podem ser abordados a partir da ótica da Nova História Cultural com o auxílio, por exemplo, da categoria e/ou noção de "Imaginário", que Jean-Claude Schmitt define como "uma realidade coletiva que consiste em narrativas míticas, em ficções, em imagens, partilhadas pelos atores sociais. Toda sociedade, todo grupo constituído produz um imaginário, sonhos coletivos, garantidores de sua identidade" 35 .

John Carey é um dos que exploram esta possibilidade. Ele considera a dupla troca de mundos feita por Nera em sua Echtra como "perplexa e surreal" ${ }^{36}$. É preciso ficar atento às camadas de narrativas e intertextualidades conectadas para compreensão do texto. $\mathrm{O}$ autor nos lembra, por exemplo, que Thuneysen cogitou que a Echtra fosse, na verdade, "Zwei Paralel-Erzählungen verschmolzen", ou seja: duas narrativas fundidas em uma só e que Séamus Ó Duilearga afirmou que o primeiro episódio (do cadáver de volta à vida após Nera colocar-lhe a faixa de vime no tornozelo) já estava completo, sendo uma narrativa separada do restante das aventuras da Echtra. Carey, rebatendo os dois argumentos, apesar de reconhecer a complexidade da trama, sustenta que linguística e estilisticamente não há diferença entre as partes da

\footnotetext{
${ }^{31}$ NÍ BHROLCHÁIN, An Introduction (...).

${ }^{32}$ NÍ BHROLCHÁIN, An Introduction (...), p. 79.

33 SANTOS, Dominique. "Uma Introdução à Escatologia Hibérnica? Algumas considerações a partir dos textos da Tradição Hiberno-latina". Revista Brasileira de História das Religiões, v. 8, 2016, p. 221-233.

34 CAMPBELL, Joseph. O Herói de Mil Faces. São Paulo: Editora Cultrix/Pensamento, 1995; CAMPBELL, Joseph. O poder do mito. São Paulo: Palas Athena, 1990.

35 SCHMITT, Jean-Claude. O corpo das imagens: ensaios sob a cultura visual na Idade Média. Bauru, SP: EDUSC, 2007, p. 351.

${ }^{36}$ CAREY, Sequence and Causation..., p. 67.
} 
narrativa, muito pelo contrário: "elas dividem uma peculiar combinação de padrões gramaticais" 37 .

De acordo com Carey, a narrativa é uma excelente oportunidade para compreendermos o imaginário irlandês sobre o outro mundo, principalmente considerando o Samhain, festividade na qual o leitor possivelmente identificará algumas semelhanças com sua ressignificação/ apropriação/ reinvenção contemporânea, o Halloween, a noite em que, de acordo com boa parte das narrativas irlandesas sobre o tema, a passagem entre este mundo e o Síd é facilitada. Segundo o autor, o fato deste importante festival ocorrer nesta data significativa que marca o início do solstício de inverno e ter esta relação com o sobrenatural "é uma evidência da posição central que os paradoxos do outro mundo ocuparam em sua visão de realidade. É totalmente apropriado que uma evidência desta mentalidade tenha sobrevivido na Echtra Nerai". 38

Também pela ótica do imaginário, Karin Olsen tenta compreender as vozes femininas do outro mundo nestas narrativas, que possuem posicionamentos ambíguos. Segundo ela, uma análise detalhada da Echtra Nerai poderá mostrar que, apesar de possuir poderes sobrenaturais, sendo um ente feérico, a mulher do Síd é subordinada a Nera e, por algum motivo difícil para o leitor moderno do texto de compreender, vivendo a ambiguidade/dualidade entre a fidelidade ao povo e ao marido humano, ela fornece uma informação favorável ao povo de Cruachan, pelo menos é de posse deste privilégio que o exército pode se preparar e marchar contra o $\operatorname{Sí}^{39}$. Analisando o mesmo tema, Patricia Ronan nos lembra que, de fato, "no fim, os humanos prevalecem sobre o povo do Síd" ${ }^{40}$.

A mulher irlandesa da Echtra Nerai é subordinada tanto ao rei do outro mundo quanto ao herói principal, que é um visitante acolhido no Síd, talvez seja possível interpretá-la como uma contrapartida à rainha Medb, que, diferentemente, tem o feitio de não se sujeitar aos homens, sobretudo a partir das descrições iniciais desta no Táin Bó Cuainlge, do qual a Echtra Nerai é uma Rémscéla ${ }^{41}$. No manuscrito MS 1318, 16, por exemplo, a Echtra aparece sob o título Táin bé Aingen.

Estudando narrativas semelhantes, embora em contextos diferentes, Aline Dias da Silveira identifica modelos distintos para construção destas personagens feéricas na literatura do período Medieval (melusinas, morganianas etc.), que, a partir de trocas culturais múltiplas, mesclam elementos pré-cristãos e cristãos $^{42}$. De acordo com a autora, "identificar a estrutura simbólica das narrativas feéricas" pode auxiliar o historiador a compreender elementos ordenadores do imaginário das sociedades em que determinado texto foi produzido. No caso de Silveira, aproximando-se e

\footnotetext{
${ }^{37}$ CAREY, Sequence and Causation ..., p. 67.

${ }^{38}$ CAREY, Sequence and Causation ..., p. 72.

${ }^{39}$ OLSEN, Karin E. Female Voices from the Otherworld: The Role of Women in the Early Irish Echtrai. In: OLSEN, Karin E; VEENSTRA, Jan R. (eds.). Airy Nothings: Imagining the Otherworld of Faerie from the Middle Ages to the Age of Reason. Brill Online, 2013, pp. 57-74.

${ }^{40}$ RONAN, Patricia. Some aspects of Echtra Nerai. Tionól - Annual colloquium da School of Celtic Studies do DIAS - Dublin Institute for Advanced Studies, 2000. Disponível apenas online a partir do seguinte link: https:/www.celt.dias.ie/publications/tionol/ronan00.pdf. Data de Acesso: 06/04/2017.

${ }^{41}$ RONAN, Some aspects (...), p. 14.

${ }^{42}$ SILVEIRA, Aline D. O Pacto das Fadas na Idade Média Ibérica. 1. ed. São Paulo: Annablume, 2013, v. 1. 142p.
} 
distanciando-se, dependendo do objetivo, da historiografia que lhe antecede, principalmente em Portugal, ela compara a estrutura simbólica destas narrativas feéricas com a estrutura ritualística e simbólica dos pactos vassálicos e matrimoniais presentes no Livro de Linhagens, de modo a compreender "mecanismos mentais coletivos" da Sociedade Medieval Portuguesa ${ }^{43}$. Para o contexto irlandês da Echtra Nerai, este imaginário acerca do papel da mulher na sociedade do período também pode ser analisado.

Estas temáticas sistematizadas a partir da Echtra Nerai poderiam ser mais exploradas pela historiografia brasileira, sobretudo utilizando-se destas ferramentas conceituais e teóricas da Nova História Cultural, pois referências a estudos desta natureza, que se concentram no contexto irlandês, ainda são raras, principalmente por não haver tradução de nenhuma destas obras do irlandês para o português.

\section{Immram Curaig Mail Dúin}

A palavra em irlandês antigo immram, plural immrama, é derivada de um verbo, imb.rá/imm.rá e significa remar, navegar, geralmente, por várias ilhas, reais ou imaginárias, até retornar para Irlanda ${ }^{44}$. A Immram Curaig Mail Dúin/A viagem do barco de Duin é uma obra sobre esta temática, provavelmente do século IX, e que nos chegou a partir de quatro manuscritos posteriores aos séculos XI e XII: o primeiro é o British Library, MS Harleian 5280 [s. xvi] ff. 12r-20v, que contém apenas a primeira parte do relato; o segundo, Trinity College Dublin, MS 131810 (H 2. 16), Yellow Book of Lecan, cols 370-391, que é o único texto que apresenta a narrativa em sua totalidade; a seguir, alguns fragmentos estão presentes no British Library MS Egerton 1782 [1516-1518] ff. 124R-125V; e, por fim, o Royal Irish Academy MS 23 E 25 (1229), Lebor na hUidre [s. xi/xii] ff. 22a-26b, apresenta fragmentos do texto em prosa ${ }^{45}$.

A Immram Curaig Mail Dúin é bem mais extensa do que a Echtra Nera. Todavia, é possível ter uma noção do que a narrativa conta a partir da síntese que elaboramos em diálogo com a obra de Hans Oskamp: Mael Dúin é um herói, filho do guerreiro Ailill e de uma freira que ele tomou à força. Logo após seu nascimento, o pai foi assassinado e ele foi criado por uma madrasta, rainha do distrito. Mael Dúin cresceu e se tornou muito bom em jogos de todos os tipos, vencia todos os oponentes. Certo dia, um dos derrotados por ele nos jogos revelou que ele não era um príncipe de verdade, mas adotado, história que a mãe adotiva se vê obrigada a confirmar, que lhe diz também que seu pai está morto. Após sugestão de um homem do lugar para que se lance ao mar a procura dos assassinos de seu pai vingando-lhe a morte, Maél Dúin vai se aconselhar com o druida de Corcomroe, que lhe explica sobre os dias favoráveis para construção de um barco e sua respectiva partida, bem como quantos homens deveriam acompanha-lo. Por sugestão do druida, a tripulação tem 17

\footnotetext{
${ }^{43}$ SILVEIRA, Aline D. "A Fada Medieval e o Destino". Mosaico (Goiânia), v. 4, 2011, p. 2-9.

${ }^{44}$ Imm-rá. In: eDIL - Electronic Dictionary of the Irish Language, Royal Irish Academy, 2007. Disponível em: <http://edil.qub.ac.uk/27905>. Data de Acesso: 06/04/2017.

${ }^{45}$ GROENEWEGEN, (Project director). CODECS - Online database and e-resources for Celtic Studies. Disponível em: <http://www.vanhamel.nl/codecs/Immram_curaig_Mail_D\%C3\%BAin>. Data de Acesso: 06/04/2017.
} 
homens e se lança ao mar, mas, logo após deixarem o porto, seus três irmãos de criação o forçam a leva-los junto, desobedecendo, então, o conselho druídico sobre a quantidade de tripulantes. Após isto, Maél Dúin navega por 31 ilhas diferentes, enfrentando inúmeras situações e vivendo várias aventuras, que vão desde a pássaros cantadores de salmos, passando por animais que se mordem uns aos outros cobrindo o lugar de sangue, até demônios, para, finalmente, encontrar a última Ilha, que é a dos assassinos de seu pai. Ao chegar lá, no entanto, eles são bem-vindos e Máel Dúin, ao invés da vingança, fica em paz com aquelas pessoas, logo depois voltando para Irlanda, após três anos e sete meses ${ }^{46}$.

Segundo Elva Johnston, o gênero Immram é constituído a partir de vários elementos, o que, de fato, pode ser percebido na narrativa de Mael Duín, pois, mesclam-se elementos da cultura céltica, como as Echtrae e suas viagens para lugares paradisíacos, cristãos, como as referências de contexto monástico e eclesiástico, além de textos bíblicos e apócrifos. De igual modo, também é possível observar exemplos da cultura clássica, tais como a Eneida ou até mesmo a Odisseia, o que, de acordo com a autora, é possível identificar na própria narrativa em questão, pois nela há referências ao Antigo Testamento, aos Evangelhos, aos Salmos, à Navigatio Sancti Brendani e à Immram Brain mac Febail ${ }^{47}$.

Para Johnston, então, a Immram Curaig Mail Dúin "cobre vários aspectos da vida medieval irlandesa". ${ }^{48}$ Por meio da análise desta narrativa podemos compreender como era imaginado o "papel da mulher, o relacionamento do guerreiro com as autoridades, a função da Igreja" ${ }^{49}$ etc. Assim, segundo a autora, as ilhas frequentadas por Duín "existem na fronteira entre o real e o outro mundo" 50 e podem ser compreendidas como "lugares de experimento social"

Um dos aspectos que podem ser explorados pela ótica da Nova História Cultural é a relação que existe entre esta e outras Immrama a as noções de Peregrinatio e Penitentia. O primeiro termo pode ser compreendido como um exílio ou viagem, geralmente em busca de objetos sagrados, visitações de lugares sagrados, em busca de isolamento etc., algo que pode estar vinculado também com a conversão ou salvação da alma ${ }^{52}$. A segunda noção, por sua vez, pode ser vista como tendo relação com a cura da doença do pecado, usando terminologia médica do período, frequentemente adotada nos penitenciais irlandeses, ou seja, um remédio para alma necessário para sua salvação $0^{53}$.

${ }^{46}$ OSKAMP, Hans P. A. The Voyage of Máel Dúin. A study in early Irish voyage literature followed by an edition of Immram Curaig Máele Dúin from the YBL in TCD, Groningen: Wolters-Noordhoff, 1970.

47 JOHNSTON, Elva. "A Sailor on the Seas of Faith: The Individual and the Church in the Voyage of Mael Dúin". In: DEVLIN, Judith e CLARKE, Howard B. (eds.). European Encounters: Essays in memory of Albert Lovett. UCD Press, 2003.

48 JOHNSTON, "A Sailor on the Seas of Faith" (...).

49 JOHNSTON, "A Sailor on the Seas of Faith" (...).

50 JOHNSTON, "A Sailor on the Seas of Faith" (...).

51 JOHNSTON, "A Sailor on the Seas of Faith" (...).

${ }^{52}$ RUFINO, José. "A noção de peregrinatio em Agostinho de Hipona". Ágora Filosófica, ano 11, n. 2, p. 113-132, jul. /Dez. 2011. P. 122; ZIERER, Adriana. Da ilha dos bem-aventurados à busca do Santo Graal: uma outra viagem pela Idade Média. São Luís: Editora UEMA, 2013, p. 31.

${ }^{53}$ FARRELL, Elaine. "Apresentação de Tese / Thesis Presentation. Taboos and Penitence: Christian Conversion and Popular Religion in Early Medieval Ireland. Thesis submitted for the degree of Doctor of Philosophy to the School of History and Archives, College of Arts and Celtic Studies, University 
Na Irlanda Antiga e Medieval Peregrinatio e Penitentia estavam, muitas vezes, imbricadas. Podemos ver isto, por exemplo na Vita Columbae, de Adomnán e também na Vita Patricii, de Muirchú Moccu Machteni. Neste segundo documento, por exemplo, Patrício condena um homem que queria lhe matar a entrar em um barco sem remos para que o mar o levasse. Guiado por Deus, ele chega a uma nova localidade na qual funda um mosteiro. Ou seja, sua Peregrinatio é, ao mesmo tempo, também uma Penitentia ${ }^{54}$. Esta temática da aventura marítima influenciará não somente a Immram abordada neste tópico, mas como outras Immrama.

$\mathrm{O}$ druida que aparece na narrativa também é uma personagem significativa, que pode ser analisado pelo viés da Nova História Cultural. Temos mais informações sobre a presença de druidas no continente europeu, pois autores gregos e latinos nos forneceram várias referências sobre eles. O Livro VI dos Comentarii De Bello Gallico, do general romano Júlio César, por exemplo, nos dá informações sobre estes sábios da cultura celta. No entanto, sabemos que se trata da autoridade sagrada responsável por realizar diversas funções relacionadas com o suprassensível.

A literatura irlandesa Antiga e Medieval os menciona com certa frequência, seja utilizando algum termo de raiz "dru" ou substituindo a nomenclatura por palavras como "sábio", "mago" etc., mas a existência de druidas após o processo de início de Cristianização da Irlanda é um fato bastante questionado e debatido pela historiografia ${ }^{55}$.

No caso de Máel Dúin, é somente após visitar o druida de Corcomroe que ele toma ciência sobre como construir o barco, o número da tripulação e a data da partida. Oskamp acredita que a definição fornecida por Amalia Draak, autora também holandesa, sobre os druidas pode auxiliar na compreensão da Immram Curaig Mail Dúin, pois é a que mais se parece com o contexto da obra: "os druidas são mágicos reais: eles sabem como as coisas devem ser feitas, eles conhecem sobre nomes e presságios, dias de sorte e de azar, "tabus", alucinações contra os inimigos etc." ${ }^{56}$ Oskamp afirma que "de fato, o druida de Corcomroe sabe a resposta para as perguntas de Máel Dúin" 57 . No entanto, ele interpreta que, apesar da recorrência do autor da Immram à palavra irlandesa dhruid, somente de forma parcial isto representa uma recorrência às narrativas anteriores, pois, continua o autor: "a Irlanda do século

College Dublin, November 2012. Thesis supervised by Dr. Elva Johnston". Medievalista. n 14, (Julhodezembro, 2013). [Consultado em 24/02/2015]. Disponível em $<$ http://www2.fcsh.unl.pt/iem/medievalista/MEDIEVALISTA14/farrell1410.html>. Data de acesso: 06/04/2017; O'LOUGHLIN, Thomas. Penitentials. In: DUFF, Séan (org.). Medieval Ireland - An Encyclopedia. Abingdon: Routledge, 2005, p. 371-372.

${ }^{54}$ SANTOS, Dominique; CORREA, Leonardo A. "Peregrinatio et Penitentia no Livro I da Vita Columbae de Adomnan (séc. VII)". Brathair (Online), v. 15, 2015, p. 132-152.

${ }^{55}$ ALDHOUSE-GREEN, Miranda J. The World of the Druids. New York, Thames and Hudson, 1997. Para maiores referências sobre druidas continentais, em português, ver: LUPI, João. Os druidas. Brathair, v. 4, n. 1, p. 70-79, 2004; e OLIVIERI, Filippo L. Os Druidas. 1. ed. São Paulo: Perspectiva, 2014, v. 1, 136p.

${ }^{56}$ DRAAK, Amalia Maartje E. "The Religion of the Celts". In: BLEEKER, Jouco; WIDENGREN, Geo. Historia Religionum; Handbook for the History of Religions, Vol. I, Religions of the Past, Leyden, 1969, pp. 629-647 [III: 10,26] Apud: OSKAMP, Hans P. A. The Voyage of Mael Dunn. Wolters-Noordhoff Publishing Company, Groningen, 1970.

${ }^{57}$ OSKAMP, The Voyage of Mael Dunn. Wolters-Noordhoff Publishing Company, Groningen, 1970. 
IX não conheceu qualquer druida em sentido algum" "58, mas conheceu "homens sábios", retomando novamente a citação de Draak, "que sabem como as coisas devem ser feitas". Oskamp acredita que o druida de Corcomroe é um destes sábios, a quem o autor da Imrram denominou com um termo "tradicional" 59 .

Como podemos observar, a intersecção entre várias tradições na composição de obras desta natureza na Irlanda Antiga e Medieval é um frequente. Além dos aspectos para os quais a já mencionada Elva Johnston chamou atenção, o tema tem sido amplamente debatido pela historiografia ${ }^{60}$.

Segundo O'Connor, desde por volta do ano 600 da era Cristã, com a produção da Amra Choluim Cille, a tradição latina e a irlandesa se desenvolveram juntas na Irlanda, por isso vemos em várias narrativas estas combinações de motivos cristãos e pagão $^{61}$. Para Brent Miles, um intercâmbio entre temáticas gregas, latinas e hebraicas marcava a produção da literatura na Irlanda Antiga e Medieval, podemos afirmar que existia "uma fascinação irlandesa com as tres linguae sacrae: hebraico, grego e latim", tanto que, de acordo com o autor "o classicismo irlandês existiu de forma colateral aos estudos clássicos [...]"62, ou seja, a recepção dos clássicos e a produção literária vernácula, como é o caso da Immram Curaig Mail Dúin, andavam juntas ${ }^{63}$.

A relação das aventuras de Mail Dúin tanto com a Imram Brain Maic Febail quanto com a Navigatio Sancti Brendani e outros textos desta tradição de composição irlandesa que mescla vários elementos da cultura cristã e secular precisa ser mais explorada pelos pesquisadores de língua portuguesa, pois, talvez também pela ausência de traduções, o tema não tem sido investigado pela historiografia.

\section{Longes mac n-Uislenn}

Loinges/Longas/Loingse/Long(a)is/longais/longe, dependendo da forma, é um termo em irlandês que significa banimento, exílio ${ }^{64}$. É este o sentido do vocábulo na Longes mac n-Uislenn, uma narrativa de exílio datada de cerca do século IX e algumas de suas partes também podem ser compreendidas como uma Rémscéla relacionada com o Táin Bó Cúailnge.

A narrativa nos chegou a partir de três manuscritos: o Trinity College Dublin, MS 1339, H. 2.18, ou Book of Leinster (LL), [s. xii] ff. 192rb linha 11 - 193rb linha 24, cujo colofão contém o seguinte: "Longas mac Usnig in-sin 7 longas Fergusa 7 aided mac n-Uisnig 7 Derdrend/O exílio dos filhos de Uisneach aqui, e o exílio de Fergus, $e$

${ }^{58}$ OSKAMP, The Voyage of Mael Dunn (...), p. 52.

${ }^{59}$ OSKAMP, The Voyage of Mael Dunn (...), p. 52.

${ }^{60}$ SANTOS, Dominique. A tradição clássica e o desenvolvimento da escrita vernacular na Early Christian Ireland: algumas considerações sobre a matéria troiana e a togail troí. História e cultura, v. 5, 2016, p. 93-110.

${ }^{61}$ O'CONNOR, Ralph. Narrative Literature and Classical Tradition. In: O'CONNOR, Ralph (ed.). Classical Literature and Learning in Medieval Irish Narrative. Studies in Celtic History XXXIV.D. S. Brewer, Cambridge, 2014, p. 15.

${ }^{62}$ MILES, Brent. Heroic Saga and Classical Epic in Medieval Ireland. Cambridge: DS Brewer, 2011, p. 34.

${ }^{63}$ MILES, Heroic Saga (...), p. 13/14.

${ }^{64}$ Loinges. In: eDIL - Electronic Dictionary of the Irish Language, Royal Irish Academy, 2007. Disponível em: <http://edil.qub.ac.uk/30536> . Data de Acesso: 06/04/2017. 
a morte dos filhos de Uisneach e de Deirdriu"; o Trinity College Dublin, MS 1318 H. 2.16, (cols 573-958), secção do Yellow Book of Lecan [s. xiv/xv] cols 749.20-753, o único manuscrito que possui título ( Loinges Mac n-Uislenn), além de um colofão no qual se lê o seguinte: “"Loinges Mac N-Uislenn 7 longes Fergusa 7 aided Derdrinne/O exílio dos filhos de Uisliu aqui, e o exílio de Fergus, e a morte de Deirdriu"; o terceiro e último é o manuscrito da British Library, MS Egerton 1782 [1516-1518] ff. 67r $69 \mathrm{v}$ linha 9. Além destes três manuscritos há duas cópias do texto, ambas a partir do MS Egerton 1782, uma delas no manuscrito Trinity College Dublin H.1.13, p. 323-27 e outra no National Library of Ireland, MS G 138, pp. 129-136 ${ }^{65}$.

A Longes mac n-Uislenn, ao mesmo tempo que conta a história do exílio dos filhos de Uisliu, contém muitas características do que seria um relato de fuga (aithid), pois parte da narrativa, e um de seus principais temas, relaciona-se com fuga de Deirdriu e Noísiu. É difícil decidir se o relato é sobre Uisliu e seus filhos ou sobre a própria Deirdriu e seu destino. A partir da síntese que apresentamos o leitor poderá formar uma opinião.

Quando os homens do Ulster festejavam em um banquete na casa de Feidlimid mac Daill, o contador de estórias de Conchobor, a mulher de Feidlimid, que estava grávida, com eles bebera e comera. Após o encerramento do festim, no entanto, aproximando-se a hora de dormir, quando a mulher se dirigia para sua cama, a criança que estava em seu ventre gritou de tal maneira que se ouviu em todo o lugar, ao que, imediatamente, todos vieram para observar o fenômeno. Diante de algo assim, o druida Cathabad foi chamado para fornecer uma explicação, algo que ele fez dizendo que isto representaria uma grande catástrofe para os homens do Ulster. Ele disse que a criança que nasceria seria uma mulher de beleza incomensurável, pela qual os homens estariam dispostos a lutar, causando inúmeros problemas, Deirdriu. Os homens do Ulster queriam matar a criança, porém o rei, Conchobar mac Nesa, afirmou que dela cuidaria no dia seguinte. Ao invés de matá-la, fez com que ela vivesse e crescesse em segredo e se tornasse a mais bela mulher que já havia habitado na Irlanda. Certo dia, ao ver o padrasto matar um bezerro na neve e um corvo bebendo o sangue deste, disse que poderia amar um homem cujas cores fossem como aquelas: seus cabelos como o corvo, bochechas como sangue e corpo como a neve. A descrição correspondia a Noísiu, um dos filhos de Uiusliu, a quem Deirdriu decidiu cortejar quando este cuidava das vacas, dirigindo-lhe por meio de metáforas sexuais relacionadas com o vocábulo do gado. Noísiu a rejeitou por conta de Conchobor, porém, Deirdriu o coagiu, ameaçando denegri-lo, fazendo-o passar vergonha, caso não a levasse com ele. O restante da narrativa conta sobre a fuga de Deirdriu e Noísiu com seus "150 guerreiros, mulheres, cães e servos" até que o amante foi encontrado e morto por Eogan mac Durthacht a pedido de Conchobor, juntamente com seus homens. Conchobor toma Deirdriu consigo, finalmente, que, após isto, "não come, não sorri e não dorme direito", apenas recita poemas de lamento por Noísiu. Não conseguindo reverter o estado de ânimo de Deirdriu, Conchobor ameaça dá-la para Eogan, que matara Noísiu, como punição. Para

${ }^{65}$ MATHIS, Kate Louise. The Evolution of Deirdriu in the Ulster Cycle. PH D Degree (PHD in Scottish and Celtic Studies). University of Edinburgh, 2010; GROENEWEGEN, (Project director). CODECS Online database and e-resources for Celtic Studies. Disponível em: <http://www.vanhamel.nl/codecs/Longes_mac_nUislenn>. Data de Acesso: 06/04/2017. 
escapar da situação, Deirdriu decide se suicidar, pula da charrua que a levava batendo a cabeça em uma rocha e morrendo ${ }^{66}$.

Novamente temos o papel de um druida, Cathbad, sobre o qual é dito, na narrativa, que é um dos mais considerados e sábios entre os druidas. Diferentemente do druida de Corcomroe da Immram Curaig Mail Dúin, Cathbad desempenha um papel maior na Longes mac n-Uislenn. Sua interpretação, em forma poética, ocupa cerca de dez versos, que contém inúmeras profecias bastante detalhadas sobre o futuro de Deirdriu, Conchobor e os guerreiros do Ulster ${ }^{67}$, certamente um tema de interesse para Nova História Cultural.

Outras temáticas que podem ser exploradas nesta narrativa são derivadas das aventuras decorridas do exílio e fuga dos filhos Uiusliu, da jornada destes entre a Irlanda e a Escócia e, claro, relacionadas com Deirdriu, que é uma das personagens mais conhecidas da literatura irlandesa do período, sendo representada até a contemporaneidade em inúmeras peças de teatro, poemas, músicas etc. Deirdriu é geralmente referenciada pelo epípeto Deirdre, ou Derdiu, dos sofrimentos (Deirdre na Bhróin, em irlandês/Deirdre of the Sorrows, em inglês). A história da literatura, das mulheres, dos papéis de gênero, da sexualidade e temáticas semelhantes tem tentando analisar a função de Deirdriu nesta narrativa, e outras que se seguiram após esta, para, por meio dela, tentar compreender representações e práticas sociais da Irlanda do período de produção da obra. Ou seja, há uma historiografia ampla sobre o tema ${ }^{68}$, que oferta várias possibilidades para uma abordagem pelo viés que temos apontado neste artigo.

\section{Fís Adamnáin}

Há vários textos em irlandeses, ou produzidos por irlandeses, que tem como temática visões de lugares relacionados com o outro mundo, pagão e cristão, ou a combinação de ambos. Alguns destes textos foram compostos em língua irlandesa, como, por exemplo, os títulos mencionados na "lista a" e "lista b" (Fís Mná Nemid, Fís Comchobair etc); outros foram compostos em Latim, como a Visio Tnugdail, o Purgatorium Sancti Patricii ou a Navigatio Brendani. A Fís Admnáin, ou Visão de Adamnáin, último texto que consideramos neste artigo, é uma destas Físi.

${ }^{66}$ HULL, Vernam (ed. and tr.), Longes mac n-Uislenn: The exile of the sons of Uisliu, The Modern Language Association of America 16, New York: Modern Language Association of America, 1949. Digitalizado pelo Humanities Computing Project "CELT: The Corpus of Eletronic Texts", subsidiado pela School of History, University College, Cork. Disponível online no seguinte link: < http://www.ucc.ie/celt/published/T301020B/>, consultado em: 02/01/2017; BITEL, Lisa M. Land of Women. Tales of Sex and Gender from Early Ireland. Ithaca and London, Cornell University Press, 1998, p. 53.

${ }^{67}$ HULL, (ed. and tr.), Longes mac n-Uislenn (...), fragmentos 4, contendo dois versos; 5 , contendo 6 versos, e referências esporádicas em outros trechos do documento, p. 61/62.

${ }^{68}$ JOHNSTON, Elva. "Kingship made real? Power and the public world in Longes Mac nUislenn". In: EDMONDS, Fiona; RUSSEL, Paul (eds.). Tome: Studies in Medieval Celtic History and Law in Honour of Thomas Charles-Edwards. Woodbridge, 2011, p. 202-6. MATHIS, Kate Louise. The Evolution of Deirdriu in the Ulster Cycle. PH D Degree (PH D in Scottish and Celtic Studies). University of Edinburgh, 2010. 
Adamnán foi um abade de Iona (679-704), autor da Vita Columbae, que conta a vida do santo irlandês Colmcille, ou São Columba. A intitulada Fís conta uma visão que Admnán teria tido durante as comemorações do dia de São João Batista, quando sua alma teria deixado o corpo e, guiado por um anjo, experimentado as sensações do céu e do inferno. Embora com algumas diferenças fundamentais (separação entre corpo e alma; existência do Purgatorium etc), mas também muitas semelhanças, a Fís Adamnáin é anterior tanto à Visio Tnugdail quanto ao Purgatorium Patricii. Considerando isso, C.S. Boswell, com um pouco de romantismo, localizou Adamnán como precursor de Dante, por exemplo ${ }^{69}$. No entanto, Mac Cana nos lembra que a Fís Fursa/Visão de Fursa (e não de Adamnáin) é o texto mais antigo deste gênero que conhecemos, já mencionado por Beda em sua Historia Ecclesiastica ${ }^{70}$.

Há vários tópicos encontrados na Fís Adamnáin que podem ser estudados pela perspectiva proposta: a relação de Adamnán e de sua Fís com viagens para o outro mundo realizadas antes dele, geralmente por autoridades da tradição cristã; sua separação entre corpo e alma; a imagem da terra dos santos; a representação do trono divino e de sua presença; a cidade celestial, juntamente com seus habitantes; o lugar dos excluídos; a jornada de Adamnán pelos sete céus, um deles no qual é possível conhecer "as dores purgatórias"; o julgamento da alma e o destino dos condenados; a representação do inferno; a classificação dos crimes e suas respectivas punições; o retorno de Adamnán ao céu, sua restauração ao corpo e respectiva volta para contar o que viu etc ${ }^{71}$.

A Fís Adamnáin pode ser encontrada nos seguintes manuscritos: Royal Irish Academy, MS 23 E 25 (1229), Lebor na hUidre [s. xi/xii] ff. 27a-31b; Royal Irish Academy, MS 23 P 16, Leabhar Breac [s. xv] pp. 253b-256a (facs.); Bibliothèque nationale de France, MS Celtique 1 (24682), [s. xv], ff. 95rb-98vb; Royal Irish Academy, MS 23 O 48a (476), Liber Flavus Fergusiorum, parte 1 [c. 1435-1440] ff. 17vb-20va; e uma versão menor no Trinity College, MS 1318, (H 2.16) (cols 573958) (H 2. 16), Secção do Yellow Book of Lecan [s. xiv/xv] cols 709-713 ${ }^{72}$.

Além dos temas específicos que compõem a Fís Adómnain, a historiografia tem recorrido a esta e outras Físi para tentar compreender, por exemplo, as noções, já mencionadas de Peregrinatio e Penitentia, o papel da escatologia nestas obras, a espiritualidade monástica na Irlanda Medieval ${ }^{73}$; a transformação da Igreja irlandesa nos séculos XII e XIII ${ }^{74}$; a relação da "Saga" heroica e dos épicos clássicos na Irlanda

${ }^{69}$ BOSWELL, Charles S. An Irish precursor of Dante: a study on the vision of Heaven and Hell ascribed to the eighth-century Irish Saint Adamnán, with translation of the Irish text, London, 1908.

${ }^{70}$ MAC CANA, Proinsias. The learned (...), p. 107.

71 BOSWELL, An Irish precursor of Dante (...). DILLON, Early Irish Literature (...). STOKES, Whitley. Fis Adamnain slicht Libair na huidre. Adamnán's Vision: Transcribed and Translated from the Book of the Dun Cow, with Notes. Simla, 1870. WINDISCH, Ernst (ed.), Irische Texte mit Wörterbuch, 4 vols, vol. 1, Leipzig, 1880, p. 165-196. Disponível em: $<$ https://archive.org/details/irischetextemit00lucagoog > . Data de Acesso: 06/04/2017.

72 GROENEWEGEN, (Project director). CODECS - Online database and e-resources for Celtic Studies. Disponível em: <http://www.vanhamel.nl/codecs/F\%C3\%ADs_Adomn\%C3\%A1in>. Data de Acesso: 06/04/2017.

${ }^{73}$ RITARI, Katja. Pilgrimage to heaven: eschatology and monastic spirituality in early medieval Ireland, Studia Traditionis Theologiae 23, Turnhout: Brepols, 2016.

${ }^{74}$ FLANAGAN, Marie Therese. The Transformation of the Irish Church in the Twelfth and Thirteenth Centuries. Woodbridge: Boydell Press, 2010. 
Medieval ${ }^{75}$; e, claro, a relação da Fís Adómnain com outras Físi e com as obras posteriores mencionadas, sobretudo o Purgatorium Patricii, por ser uma das obras fundamentais na discussão sobre o Purgatorium enquanto um lugar ${ }^{76}$, independentemente de seu nascimento literário no século XII ou não ${ }^{77}$. Além de todas estas possibilidades, como afirma Dillon, "as Visões Irlandesas contêm evidências valiosas sobre o que era lido e estudado na Irlanda dos séculos VIII, IX e X"78. No Brasil, o tema tem sido amplamente estudado pela historiadora Adriana Maria de Souza Zierer, da Universidade Estadual do Maranhão, tanto publicando sozinha quanto em regime de co-autoria, principalmente a partir da Visão de Túndalo e sua recepção em Portugal $^{79}$, mostrando que a temática oferece inúmeras possibilidades de estudo.

\section{Considerações Finais}

Neste artigo, ao invés de adotarmos as divisões em ciclos comuns nas histórias modernas da literatura irlandesa (Ulster, Feniano, Mitológico e Histórico), em conjunto com as categorias das "aventuras", "viagens", "visões" e "poesia", preferimos dialogar com as divisões estabelecidas nos manuscritos medievais, principalmente as chamadas "lista a" e "lista b". Dentre as inúmeras obras do período, selecionamos quatro gêneros, sendo uma narrativa dentre cada um deles (a "Echtra Nerai (EN)"/As aventuras de Nera; a Immram Brain/A viagem de Bran; a Longes mac n-Uislenn/O exílio dos filhos de Uisliu; e a Fís Adamáin/Visão de Adamnán) de modo a apontar como estas podem ser utilizadas como fontes históricas para a escrita de uma História Cultural da Irlanda Antiga e Medieval.

Até mesmo em língua inglesa trabalhos recentes vêm sendo produzido sobre este material, alguns mencionados neste artigo. Em língua portuguesa, principalmente no Brasil, somente nas últimas décadas os estudos célticos e irlandeses tem ganhado mais força, com a fundação da ABEI - Associação Brasileira de Estudos Irlandeses (1989) e da BRATHAIR - Revista de Estudos Célticos e Germânicos (2001); da Cátedra W.B. Yeats de Estudos irlandeses da USP (2009), do recém-criado NEI Núcleo de Estudos Irlandeses da Universidade Federal de Santa Catarina (2016) e o

\footnotetext{
${ }^{75}$ MILES, Brent. Heroic Saga (...).

${ }^{76}$ SANTOS, Dominique. Patrício: A Construção da Imagem de um Santo/How the Historical Patrick Was Transformed into the St. Patrick of Religious Faith. 1. ed. New York; Lampeter: The Edwin Mellen Press, 2013.

${ }^{77}$ LE GOFF, Jacques. O Nascimento do Purgatório. São Paulo: Estampa, 1995.

${ }^{78}$ DILLON, Early Irish Literature (...), p. 132.

79 ZIERER, Adriana. "A Visão de Túndalo no Contexto das Viagens Imaginárias ao Além Túmulo: religiosidade, imaginário e educação no medievo". Notandum (USP), v. 32, 2013, p. 101-124; ZIERER, Adriana. "Viagens ao Paraíso Terreal e suas influências célticas". In: KESTLER, Izabela Maria Furtado (org.). Estudos Anglo-Germânicos em Perspectiva. 1ed. Rio de Janeiro: Editora da UFRJ, 2002, p. 170-175; ZIERER, Adriana. "A Viagem de S. Brandão e os Imrama Célticos". In: LUPI, João; DALRI JÚNIOR, Arno (orgs.). Humanismo Medieval. 01ed. Ijuí: Ijuí, 2005, v. 01, p. 13-30; ZIERER, Adriana; OLIVEIRA, Solange P. "A Visão de Túndalo. Harmonia, Paraíso e Salvação no Além Medieval”. Mirabilia (Vitória. Online), v. 16, 2013, p. 222-247; ZIERER, Adriana; OLIVEIRA, Solange P. "Poder e controle eclesiástico através dos castigos infernais na Visão de Túndalo". Revista de História Hélikon, v. 2, 2014, p. 37-54.
} 
estabelecimento de alguns docentes que estudam a temática, principalmente em Departamentos de Letras, Literatura e História espalhados, embora ainda de forma bastante tímida, pelo País. Apesar disso, não temos estudos sistemáticos sobre este tipo de documentação, além do déficit evidente no que diz respeito à traduções do irlandês para o português. Se este artigo conseguiu apontar algumas lacunas e, respectivamente, caminhos que podem ser trilhados por futuros pesquisadores, chamando atenção para alguns temas que podem ser explorados pelo viés da História Cultural no que diz respeito a estas narrativas "célticas" de viagem para o outro mundo, sua função foi cumprida com êxito.

\section{gONOR}

\section{RESUMO}

As nomenclaturas utilizadas para sistematizar as narrativas literárias produzidas em língua irlandesa na Antiguidade e no Medievo tem sido as mais variadas. $\mathrm{Na}$ modernidade, são recorrentes as divisões em ciclos (Ulster, Feniano, Mitológico e Histórico), aventuras, viagens, visões e poesia. Nas duas maiores listas medievais contendo classificações deste mesmo material, denominadas na historiografia específica da área como "lista a" e "lista b", todavia, outras nomenclaturas são utilizadas, gerando uma percepção distinta destas narrativas. Considerando a sistematização medieval, este artigo aborda as narrativas "célticas" de viagens para o outro mundo, denominadas na "lista a" e na "lista b" como: "Echtra", "Imram", "Longes" "Fís", apontando como elas podem ser utilizadas como fontes históricas para a escrita de uma História Cultural da Irlanda Antiga e Medieval.

Palavras Chave: Narrativas "Célticas" de Viagem para o outro mundo; História da Irlanda Antiga e Medieval; História Cultural.

\begin{abstract}
The nomenclatures used to systematize literary narratives produced in the Irish language in Antiquity and in the Middle Ages have been the most varied. Today, the division of these narratives in cycles (Ulster, Fenian, Mythological, and Historical), adventures, travels, visions, and poetry is frequent. In the two major medieval lists containing classifications of the same material, named by the historiography of this field as 'list a' and "list b", however, other nomenclatures are used, allowing a different perception of these narratives. Taking the medieval systematization into account, this article approaches the 'Celtic' narratives of journeys to another world, denominated in 'list a' and 'list b' as 'Echtra', 'Imram','Longes' and 'Fís', pointing out how they can be used as historical sources for the writing of a Cultural History of Ancient and Medieval Ireland.
\end{abstract}

Keywords: 'Celtic' Narratives to another world; Ancient and Medieval Irish History; Cultural History.

Artigo recebido em 06 abr. 2017.

Aprovado em 17 mai. 2018. 